\title{
Synthesis and structural and magnetic characterisation of copper(II) complexes of mixed phosphonate-antimonate ligands $\uparrow$
}

\author{
Shoaib Ali, Christopher A. Muryn, Floriana Tuna and Richard E. P. Winpenny* \\ Received 7th July 2009, Accepted 24th October 2009 \\ First published as an Advance Article on the web 20th November 2009 \\ DOI: 10.1039/b913467k
}

A polynucleating oxygen donor ligand based on condensation of $p$-chlorophenylstibonic acid $\left(\mathrm{ArSbO}_{3} \mathrm{H}_{2}\right)$ and $t$-butylphosphonic acid is reported. [ $\left.(\mathrm{SbAr})_{2} \mathrm{O}\left(\mathrm{HO}_{3} \mathrm{P}^{\mathrm{t}} \mathrm{Bu}\right)_{6}\right]$ contains two antimony centres, bridged by an oxide and two hydrogen phosphonates. Reaction with copper acetate under solvothermal conditions produces four new polymetallic copper complexes. With pyridine used as a base the major product is a tetracopper cage, $\left[\mathrm{Cu}_{4} \mathrm{O}_{2}(\mathrm{SbAr})_{2}\left(\mathrm{O}_{3} \mathrm{P}^{\mathrm{t}} \mathrm{Bu}\right)_{2}\left(\mathrm{O}_{2} \mathrm{CMe}\right)_{2}(\mathrm{OMe})_{6}\right]$, with the four copper centres arranged in a rhombus; a minor product is a tricopper complex, $\left[\mathrm{Cu}_{3} \mathrm{O}_{4}(\mathrm{SbAr})_{2}\left(\mathrm{O}_{3} \mathrm{P}^{\mathrm{t}} \mathrm{Bu}\right)_{4}(\mathrm{py})_{3}\right]$. With LiOMe as base the major product is again the tetranuclear cage, but the minor product is a heterometallic cage, $\left[\mathrm{Cu}_{5} \mathrm{Li}_{4} \mathrm{O}_{6}(\mathrm{SbAr})_{4}\left(\mathrm{O}_{3} \mathrm{P}^{\mathrm{t}} \mathrm{Bu}\right)_{6}\left(\mathrm{O}_{2} \mathrm{CMe}\right)_{2}(\mathrm{OMe})_{4}\right.$ $\left.(\mathrm{MeOH})_{4}\right]$. With 2,6-lutidine as base an octametallic complex is formed, $\left[\mathrm{Cu}_{8} \mathrm{O}_{4}(\mathrm{SbAr})_{2}\left(\mathrm{O}_{3} \mathrm{P}^{\mathrm{t}} \mathrm{Bu}\right)_{6}{ }^{-}\right.$ $\left(\mathrm{O}_{2} \mathrm{CMe}\right)_{4}$ (lutidine $\left.)_{2}\right]$. Magnetic studies show both anti-ferromagnetic and weak ferromagnetic exchange between the copper centres in these new complexes.

\section{Introduction}

A number of groups have been examining the use of phosphonate ligands to make polymetallic cage complexes. Our work in this area was originally inspired by a paper by Kingsley and Chandrasekhar, who showed that phosphonates could be used as bridging ligands to make a large copper(II) cage, with pyrazoles as co-ligands. ${ }^{1}$ Using this approach we have made a number of cobalt, ${ }^{2}$ nickel $^{3}$ and vanadium cages. ${ }^{4}$ We also examined the reaction of phosphonates with pre-formed carboxylate cage compounds, producing new cages with iron ${ }^{5}$ and manganese. ${ }^{6}$ This reaction, where carboxylates are displaced by phosphonates causing growth of the cage complex due to the greater denticity of the phosphonate ligand, has been pursued with great success by Konar and Clearfield, ${ }^{7}$ and a number of other groups. ${ }^{8}$ Both tactics are used to avoid the insolubility of metal phosphonates which had previously restricted their uses in making cage complexes, with a much greater prevalence of phosphonates being used in making 2D-materials. ${ }^{9}$

To extend this work we examined antimonates as possible ligands, and found polycondensation products which suggest antimonates could be used as inorganic cryptands. ${ }^{10}$ As no condensation is observed for phosphonates, and polycondensation is found for antimonates we reasoned that mixing phosphonic acids and stibonic acids might lead to partial condensation and polydentate oxygen donor ligands. We reported a preliminary communication on this subject recently, and the resulting cobalt(II) complexes. ${ }^{11}$ Main group phosphonates have been studied for a number of years by Roesky ${ }^{12}$ and others, ${ }^{13}$ but not, to our knowledge, used as ligands for transition metals. Here we report

School of Chemistry, The University of Manchester, Oxford Road, Manchester, UK M13 9PL. E-mail: richard.winpenny@manchester.ac.uk; Fax: $+44-161-275-4616$

$\dagger$ CCDC reference numbers 739330-739333. For crystallographic data in CIF or other electronic format see DOI: $10.1039 / \mathrm{b} 913467 \mathrm{k}$ an investigation of the coordination chemistry of copper(II) with one of these phosphonate-antimonate ligands.

\section{Experimental}

\section{Preparation of compounds}

All reagents, metal salts and ligands were used as obtained from Aldrich. Analytical data were obtained by the microanalytical service of the University of Manchester and are given in Table 1.

\section{$\left[(\mathrm{SbAr})_{2} \mathrm{O}\left(\mathrm{HO}_{3} \mathrm{P}^{\mathrm{B}} \mathrm{Bu}\right)_{6}\right] \mathbf{1}$}

p-Chlorophenylstibonic acid $\left(\mathrm{ArSbO}_{3} \mathrm{H}_{2}\right)(0.4 \mathrm{~g}, 1.4 \mathrm{mmol})$ and $t$-butylphosphonic acid $0.43 \mathrm{~g}(2.8 \mathrm{mmol})$ were added to $\mathrm{MeCN}$ $(20 \mathrm{ml})$ and the mixture was stirred for $24 \mathrm{~h}$. It was then filtered and filtrate was allowed to crystallise by slow evaporation. Crystals of 1 formed after one week. Yield: $60 \%$.

\section{$\left[\mathrm{Cu}_{4} \mathrm{O}_{2}(\mathrm{SbAr})_{2}\left(\mathrm{O}_{3} \mathrm{P}^{t} \mathrm{Bu}\right)_{2}\left(\mathrm{O}_{2} \mathrm{CMe}\right)_{2}(\mathrm{OMe})_{6}\right] 2$}

Compound 1 ( $0.13 \mathrm{~g}, 0.10 \mathrm{mmol})$ and copper acetate $(0.08 \mathrm{~g}$, $0.40 \mathrm{mmol})$ were added to methanol $(6 \mathrm{~mL})$ and pyridine $(0.1 \mathrm{~mL})$ in a Parr digestion bomb. The bomb was sealed and heated at $100{ }^{\circ} \mathrm{C}$ for $12 \mathrm{~h}$ and then cooled slowly. Blue crystals of 2 were obtained directly from the reaction. Yield: $40 \%$

\section{$\left[\mathrm{Cu}_{3} \mathrm{O}_{4}(\mathrm{SbAr})_{2}\left(\mathrm{O}_{3} \mathrm{P}^{\mathrm{t}} \mathrm{Bu}\right)_{4}(\mathrm{py})_{3}\right] 3$}

The same procedure was followed as for $\mathbf{2}$. The crystals of $\mathbf{2}$ were removed, and the blue solution remaining was filtered and allowed to evaporate slowly. Blue crystals of $\mathbf{3}$ were formed after several days. Yield: $30 \%$

\section{$\left[\mathrm{Cu}_{5} \mathrm{Li}_{4} \mathrm{O}_{6}(\mathrm{SbAr})_{4}\left(\mathrm{O}_{3} \mathrm{P}^{\mathrm{t}} \mathrm{Bu}\right)_{6}\left(\mathrm{O}_{2} \mathrm{CMe}\right)_{2}(\mathrm{OMe})_{4}(\mathrm{MeOH})_{4}\right] 4$}

Compound $1(0.13 \mathrm{~g}, 0.10 \mathrm{mmol})$ and copper acetate $(0.08 \mathrm{~g}$, $0.40 \mathrm{mmol})$ were added to methanol $(6 \mathrm{~mL})$ and LiOMe $(0.023 \mathrm{~g}$, 
Table 1 Analytical data for compounds 1-5

\begin{tabular}{|c|c|c|c|c|c|c|c|}
\hline Compound & Formula & \multicolumn{6}{|c|}{ Analytical data ${ }^{a}$} \\
\hline 2 & $\mathrm{C}_{30} \mathrm{H}_{50} \mathrm{Cl}_{2} \mathrm{Cu}_{4} \mathrm{O}_{18} \mathrm{P}_{2} \mathrm{Sb}_{2}$ & $26.80(27.10)$ & $3.72(3.79)$ & $17.77(19.12)$ & - & $3.81(4.66)$ & $19.20(18.31)$ \\
\hline 3 & $\mathrm{C}_{43} \mathrm{H}_{59} \mathrm{Cl}_{2} \mathrm{Cu}_{3} \mathrm{~N}_{3} \mathrm{O}_{16} \mathrm{P}_{4} \mathrm{Sb}_{2}$ & $33.05(34.36)$ & $4.19(3.95)$ & $11.41(12.68)$ & $2.62(2.79)$ & $7.70(8.24)$ & $14.90(16.20)$ \\
\hline $4^{b}$ & $\mathrm{C}_{60} \mathrm{H}_{104} \mathrm{Cl}_{4} \mathrm{Cu}_{5} \mathrm{Li}_{4} \mathrm{O}_{36} \mathrm{P}_{6} \mathrm{Sb}_{4}$ & $25.97(28.43)$ & $3.66(4.31)$ & $11.45(12.02)$ & & $6.84(7.10)$ & $17.95(18.48)$ \\
\hline 5 & $\mathrm{C}_{58} \mathrm{H}_{92} \mathrm{Cl}_{2} \mathrm{Cu}_{8} \mathrm{~N}_{2} \mathrm{O}_{30} \mathrm{P}_{6} \mathrm{Sb}_{2}$ & $29.96(30.20)$ & $3.90(4.02)$ & $21.88(22.04)$ & $1.31(1.21)$ & $7.32(8.05)$ & $10.66(10.56)$ \\
\hline
\end{tabular}

Table 2 Crystal data for compounds 1-5

\begin{tabular}{|c|c|c|c|c|c|}
\hline Compound & 1 & 2 & 3 & 4 & 5 \\
\hline Formula & $\mathrm{C}_{36} \mathrm{H}_{62} \mathrm{Cl}_{2} \mathrm{O}_{19} \mathrm{P}_{6} \mathrm{Sb}_{2}$ & $\mathrm{C}_{30} \mathrm{H}_{50} \mathrm{Cl}_{2} \mathrm{Cu}_{4} \mathrm{O}_{18} \mathrm{P}_{2} \mathrm{Sb}_{2}$ & $\mathrm{C}_{45} \mathrm{H}_{67} \mathrm{Cl}_{2} \mathrm{Cu}_{3} \mathrm{~N}_{3} \mathrm{O}_{19} \mathrm{P}_{4} \mathrm{Sb}_{2}$ & $\begin{array}{l}\mathrm{C}_{61} \mathrm{H}_{104} \mathrm{Cl}_{4} \mathrm{Cu}_{5} \mathrm{Li}_{4} \mathrm{O}_{37} \mathrm{P}_{6} \mathrm{Sb}_{4} . \\
\mathrm{C}_{0.26} \mathrm{H}_{1.08} \mathrm{O}_{0.71}\end{array}$ & $\mathrm{C}_{58} \mathrm{H}_{92} \mathrm{Cl}_{2} \mathrm{Cu}_{8} \mathrm{~N}_{2} \mathrm{O}_{30} \mathrm{P}_{6} \mathrm{Sb}_{2}$ \\
\hline $\mathbf{M}_{r}$ & 1299.08 & 1329.20 & 1582.92 & 2605.19 & 2305.88 \\
\hline Crystal system & Triclinic & Monoclinic & Triclinic & Triclinic & Monoclinic \\
\hline Space group & $P \overline{1}$ & $P 2_{1} / n$ & $P \overline{1}$ & $P \overline{1}$ & $P 2_{1} / n$ \\
\hline$a / \AA ̊$ & $10.4506(19)$ & $13.2383(4)$ & $11.6323(2)$ & $14.1112(3)$ & $4.3110(3)$ \\
\hline$b / \AA ̊$ & $11.6444(18)$ & $11.1442(3)$ & $13.2236(4)$ & $15.8788(3)$ & $21.4852(4)$ \\
\hline$c / \AA$ & $22.684(3)$ & $15.5501(4)$ & $21.2764(6)$ & $23.7777(5)$ & $14.3972(3)$ \\
\hline$\alpha\left(^{\circ}\right)$ & $94.982(13)$ & 90.00 & $91.158(2)$ & $92.306(2)$ & 90.00 \\
\hline$\beta\left(^{\circ}\right)$ & $99.542(14)$ & $99.411(3)$ & $102.161(2)$ & $92.089(2)$ & $103.040(2)$ \\
\hline$\gamma\left({ }^{\circ}\right)$ & $90.679(13)$ & 90.00 & $104.612(2)$ & $110.555(2)$ & 90.00 \\
\hline$V / \AA^{3}$ & $2711.0(8)$ & $2263.23(11)$ & $3086.51(14)$ & 4977.32(18) & $4312.62(15)$ \\
\hline Crystal size/mm & & $0.30 \times 0.20 \times 0.20$ & $0.30 \times 0.20 \times 0.20$ & $0.35 \times 0.30 \times 0.20$ & $0.30 \times 0.20 \times 0.15$ \\
\hline$\rho_{\mathrm{c}} / \mathrm{g} \mathrm{cm}^{-3}$ & 1.591 & 1.951 & 1.703 & 1.743 & 1.776 \\
\hline Crystal shape and colour & colourless block & blue block & green block & green block & blue block \\
\hline Total reflns & 29942 & 15153 & 26149 & 47395 & 31096 \\
\hline ind.reflns $/ R$ int & $9551 / 0.0604$ & $4603 / 0.0179$ & $12539 / 0.0270$ & 20218 & 8773 \\
\hline reflns with $I>2 \sigma(I)$ & 5296 & 4066 & 9374 & 14707 & 7067 \\
\hline Parameters & 604 & 269 & 719 & 1229 & 500 \\
\hline restraints & 0 & 0 & 0 & 656 & 0 \\
\hline$R_{1}, \mathrm{w} R_{2}$ & $0.0547,0.1259$ & $0.0209,0.0524$ & $0.0285,0.0666$ & $0.0444,0.0968$ & $0.0296,0.0724$ \\
\hline goodness of fit & 0.95 & 1.094 & 0.993 & 1.021 & 1.054 \\
\hline largest residuals/e $\AA^{-3}$ & 2.45 & 0.66 & 0.87 & 2.62 & 1.13 \\
\hline
\end{tabular}

$0.6 \mathrm{mmol}$ ) in a Parr digestion bomb. The bomb was sealed and heated at $100^{\circ} \mathrm{C}$ for $12 \mathrm{~h}$ and then cooled slowly. The blue solution was filtered and coloured crystals of $\mathbf{4}$ were obtained by slow evaporation of the filtrate. Yield: $5 \%$.

\section{$\left.\left[\mathrm{Cu}_{8} \mathrm{O}_{4}(\mathrm{SbAr})_{2}\left(\mathrm{O}_{3} \mathrm{P}^{\mathrm{t} B u}\right)_{6}\left(\mathrm{O}_{2} \mathrm{CMe}\right)_{4} \text { (lutidine }\right)_{2}\right] 5$}

Compound $1(0.13 \mathrm{~g}, 0.10 \mathrm{mmol})$ and copper acetate $(0.08 \mathrm{~g}$, $0.40 \mathrm{mmol})$ were added to $\mathrm{MeCN}(6 \mathrm{~mL})$ and 2,6-lutidine $(0.1 \mathrm{~mL})$ in a Parr digestion bomb. The bomb was sealed and heated at $100^{\circ}$ $\mathrm{C}$ for $12 \mathrm{~h}$ and then cooled slowly. Blue crystals of $\mathbf{5}$ were obtained directly from the reaction. Yield: $35 \%$.

\section{Structure determinations}

Data were collected on a Oxford Xcalibur CCD diffractometer (Mo-K $\alpha, \lambda=0.71069 \AA$ ). In all cases the selected crystals were mounted on the tip of a glass pin using Paratone-N oil and placed in the cold flow $(100 \mathrm{~K})$ produced with an Oxford Cryocooling device. ${ }^{11}$ Complete hemispheres of data were collected using $\omega$ scans $\left(0.3^{\circ}, 30 \mathrm{~s} /\right.$ frame $)$. Integrated intensities were obtained with SAINT $+{ }^{12}$ and they were corrected for absorption using
SADABS. ${ }^{12}$ Structure solution and refinement was performed with the SHELX-package. ${ }^{12}$ The structures were solved by direct methods and completed by iterative cycles of $\Delta F$ syntheses and full-matrix least-squares refinement against $F^{2}$. Crystal data are given in Table 2.

\section{Magnetic measurements}

The magnetic properties of polycrystalline samples were investigated in the temperature range $2-300 \mathrm{~K}$, by using a Quantum Design MPMS XL SQUID magnetometer equipped with a $7 \mathrm{~T}$ magnet. Magnetic susceptibility data were corrected for the diamagnetism of the compounds by using Pascal constants and for the diamagnetic contribution of the sample holder by measurement.

\section{Results}

Compound $\mathbf{1}$ is made straightforwardly from mixing $p$-chlorophenylstibonic acid $\left(\mathrm{ArSbO}_{3} \mathrm{H}_{2}\right)$ and $t$-butylphosphonic acid together in $\mathrm{MeCN}$ with a $1: 2$ mole ratio. The crystal structure (Fig. 1) shows two $\mathrm{Sb}$ centres bridged by a $\mu_{2}$-oxide and two 


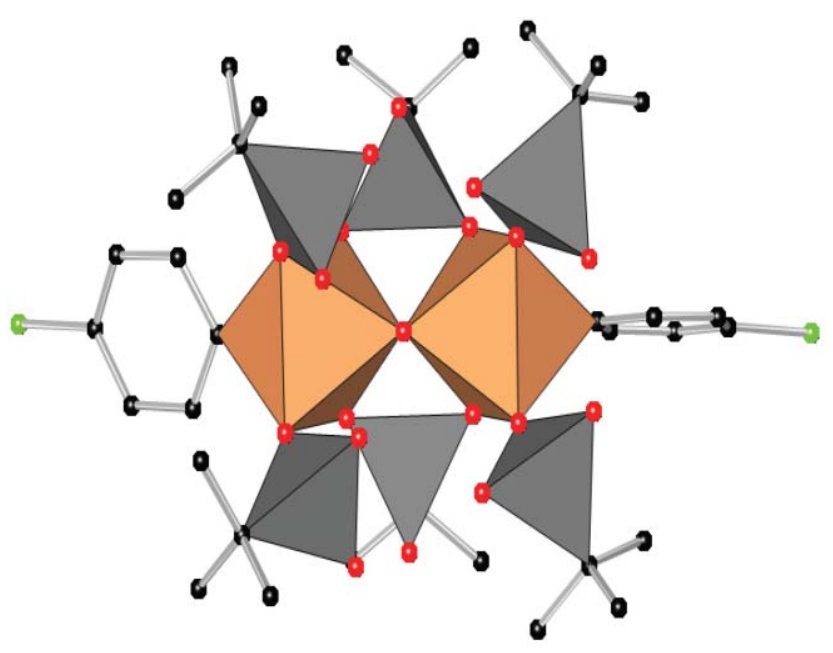

Table 3 Selected bond lengths $(\AA)$ and angles $\left({ }^{\circ}\right)$ in compound 2

\begin{tabular}{llll}
\hline $\mathrm{Cu} 1-\mathrm{O} 5$ & $1.8971(17)$ & $\mathrm{Cu} 1-\mathrm{O} 9$ & $1.9197(17)$ \\
$\mathrm{Cu} 1-\mathrm{O} 1$ & $1.9534(17)$ & $\mathrm{Cu} 1-\mathrm{O} 7$ & $2.0155(17)$ \\
$\mathrm{Cu} 1-\mathrm{O} 2$ & $2.3813(16)$ & $\mathrm{Cu} 2-\mathrm{O} 5$ & $1.8977(17)$ \\
$\mathrm{Cu} 2-\mathrm{O} 8$ & $1.9177(17)$ & $\mathrm{Cu} 2-\mathrm{O} 2$ & $1.9571(16)$ \\
$\mathrm{Cu} 2-\mathrm{O} 4$ & $2.0111(17)$ & $\mathrm{Cu} 2-\mathrm{O} 1$ & $2.3563(16)$ \\
O5-Cu1-O9 & $168.95(7)$ & $\mathrm{O} 5-\mathrm{Cu} 2-\mathrm{O} 8$ & $169.26(7)$ \\
O5-Cu1-O1 & $93.25(7)$ & $\mathrm{O} 5-\mathrm{Cu} 2-\mathrm{O} 2$ & $93.78(7)$ \\
O9-Cu1-O1 & $94.99(7)$ & O8-Cu2-O2 & $93.62(7)$ \\
O5-Cu1-O7 & $78.90(7)$ & O5-Cu2-O4 & $79.11(7)$ \\
O9-Cu1-O7 & $92.63(7)$ & O8-Cu2-O4 & $93.06(7)$ \\
O1-Cu1-O7 & $172.04(7)$ & O2-Cu2-O4 & $172.39(7)$ \\
O5-Cu1-O2 & $94.05(6)$ & O5-Cu2-O1 & $94.61(6)$ \\
O9-Cu1-O2 & $93.73(7)$ & O8-Cu2-O1 & $93.46(7)$ \\
O1-Cu1-O2 & $86.92(6)$ & O2-Cu2-O1 & $87.54(6)$ \\
O7-Cu1-O2 & $94.87(6)$ & O4-Cu2-O1 & $95.68(6)$ \\
Cu1-O1-Cu2 & $87.98(6)$ & $\mathrm{Cu} 1-\mathrm{O} 2-\mathrm{Cu} 2$ & $87.19(6)$ \\
$\mathrm{Cu} 1-\mathrm{O} 5-\mathrm{Cu} 2$ & $134.77(9)$ & & \\
\hline
\end{tabular}

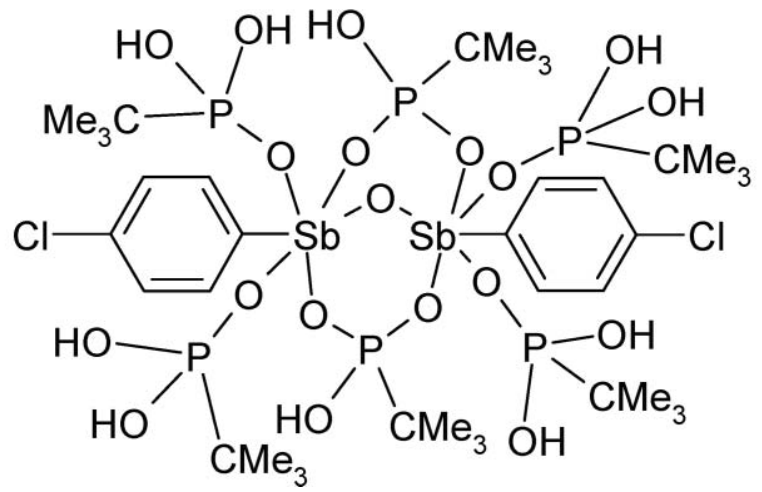

Fig. 1 The structure of $\mathbf{1}$ in the crystal showing as a polyhedral view. Colour code: $\mathrm{Sb}$, orange; $\mathrm{P}$, gray; $\mathrm{O}$, red; $\mathrm{C}$, black; $\mathrm{Cl}$, green. A line drawing of the structure is shown below.

hydrogen phosphonate ligands. Four further hydrogen phosphonates are attached to the $\mathrm{Sb}$ centres. The $\mathrm{Sb}-\mathrm{O}$ bond lengths involving the $\mu_{2}$-oxide are 1.931(5) and 1.944(5) $\AA$, while the $\mathrm{Sb}$ $\mathrm{O}$ bonds involving the phosphonates are in the range 1.982(5)2.034(5) $\AA$.

Compound 2 was obtained by the reaction of 1 with copper acetate in $\mathrm{MeOH}$ under solvothermal conditions, using pyridine as base. The crystals of $\mathbf{2}$ appeared directly upon slow cooling of the $\mathrm{MeOH}$ solution. The structure is centro-symmetric and contains four $\mathrm{Cu}$ centres arranged in a rhombus (Fig. 2). Selected bond distances and bond angles for $\mathbf{2}$ are given in Table 3. The $\mathrm{Cu} 1 \cdots \mathrm{Cu} 2$ edge of the rhombus is bridged by a $\mu_{3}$-oxide (O5) which is also attached to the $\mathrm{Sb} 1$ site. This $\mathrm{Cu} \cdots \mathrm{Cu}$ contact on this edge is $3.50 \AA$. $\mathrm{Cu} 1$ is bridged to $\mathrm{Cu} 2$ a centre by two oxygens (O1a and $\mathrm{O} 2$ ) from phosphonates and by an acetate group; this leads to a $\mathrm{Cu} \cdots \mathrm{Cu}$ distance of $3.01 \AA$. There are also four $\mu_{2}$ methoxides in the structure, bridging $\mathrm{Cu}$.. Sb contacts.

Both copper sites have square pyramidal geometry; for each $\mathrm{O} 5$, an oxygen from an acetate, and oxygen from a phosphonate and an $\mathrm{O}$-atom from the $\mu_{2}$-methoxide occupy equatorial positions. The axial position is occupied by an oxygen from a phosphonate; $\mathrm{O} 2$ for $\mathrm{Cu} 1$ and $\mathrm{O} 1$ for $\mathrm{Cu} 2$. All the equatorial bond distances are around $2.0 \AA$, while the axial $\mathrm{Cu}(1)-\mathrm{O}(2)$ bond distance is
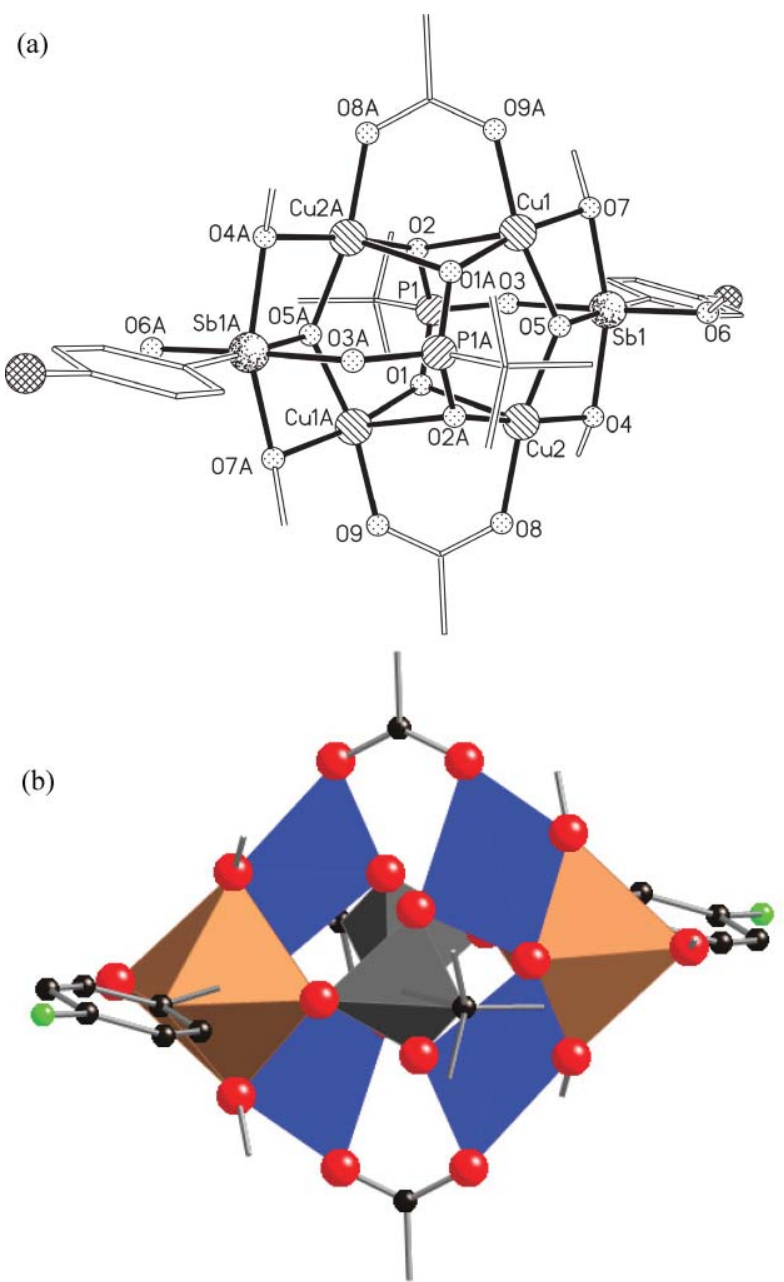

Fig. 2 The structure of 2 in the crystal shown (a) as a ball-and-stick view (aryl group on $\mathrm{Sb}$ excluded for clarity), and (b) as a polyhedral view. Colour scheme as Fig. 1, plus $\mathrm{Cu}$, blue polyhedra.

2.3813(16) A. All the bond angles are as expected for a square pyramid.

The two symmetry-equivalent $\mathrm{Sb}$ centres, are six co-ordinate and attached to one terminal methoxide (O6), two $\mu$-methoxides (O4 and $\mathrm{O} 7)$, one $\mu_{3}$-oxide (O5) and one oxygen (O3) from a phosphonate. $\mathrm{The} \mathrm{Sb}-\mathrm{O}$ bond distances again depend on the type 
of oxygen involved; the shortest bond is to O5 at 1.950(2) $\AA$; bonds to methoxide fall in the range $1.962-2.045(2) \AA$, while those to phosphonate are longest at 2.084(2) $\AA$. The bonding mode for both of the phosphonates is 5.221, with the mononucleating O-donor bound to antimony. The same product, with almost the same yield and purity was obtained by using $\mathrm{LiOMe}, \mathrm{NaOMe}, \mathrm{KOMe}$ or lutidine as a base instead of pyridine. Therefore changing base in this reaction does not change the major product obtained, however the by-products are different, with $\mathbf{3}$ obtained if pyridine is used and $\mathbf{4}$ if LiOMe is used.

Compound 3 was obtained by slow evaporation of the mother liquor after crystals of $\mathbf{2}$ were collected. The molecular structure of compound 3 is shown in Fig. 3. The structure contains two $\mathrm{Sb}$ and three $\mathrm{Cu}$ centres occupying the corners of a square pyramid. The two $\mathrm{Sb}$ centres are connected through a $\mu_{2}$-oxide (O4) and a $\mu_{3}$-oxide (O6), with $\mathrm{Sb}-\mathrm{O}$ bond distance of around $2.0 \AA$. The $\mathrm{Cu} 1$ and $\mathrm{Cu} 3$ sites have square pyramidal geometry with two oxygen donors from phosphonates $(\mathrm{O} 14$ and $\mathrm{O} 15$ for $\mathrm{Cu} 1, \mathrm{O} 10$ and $\mathrm{O} 12$ for $\mathrm{Cu} 3$ ), a $\mu_{2}$-oxide (O1 or $\mathrm{O} 5$ ) and an $\mathrm{N}$-donor from pyridine in equatorial positions, while a $\mu_{2}$-oxide (O19) occupies the axial position of each copper site. All the equatorial bond distances around these copper centres are in the range of 1.91$2.00 \AA$, while the axial Cu1-O19 bond distance is $2.527(2) \AA$. The bond angles are as expected for a square pyramid. The $\mathrm{Cu} 2$ site has a trigonal bipyramidal coordination geometry in which one pyridyl ligand and a $\mu_{3}$-oxide (O6) occupy the axial positions while three oxygen donors from phosphonates, $(\mathrm{O} 7, \mathrm{O} 11$, and $\mathrm{O} 16)$, occupy the equatorial positions of the trigonal bipyramid. All the equatorial bond distances around $\mathrm{Cu}(2)$ centre are 1.9-2.1 $\AA$, while the axial bond distances are around $1.9 \AA$. There is no trend in the $\mathrm{Sb}-\mathrm{O}$ bond lengths which fall in the range 1.971(2)-2.045(2)

$\AA$. The phosphonates show two bonding modes; three, involving $\mathrm{P} 1, \mathrm{P} 2$ and $\mathrm{P} 3$, show the 3.111 mode while the fourth bridges $\mathrm{Cu} 1$ and $\mathrm{Cu} 3$ using the 2.110 mode. The inter atomic distance between $\mathrm{Cu}(1)$ and $\mathrm{Cu}(3)$ centres is $4.18 \AA$. The selected bond distances and bond angles for compound $\mathbf{3}$ are shown in Table 4.

Compound $\mathbf{4}$ was obtained by the reaction of $\mathbf{1}$ with copper acetate in $\mathrm{MeOH}$ under solvothermal conditions, using LiOMe as base. Crystals of $\mathbf{2}$ are the major product of the reaction, and form on slow cooling of the solution within the bomb. Crystals of $\mathbf{4}$ appeared by slow evaporation of the $\mathrm{MeOH}$ solution after

Table 4 Selected bond lengths $(\AA)$ and angles $\left(^{\circ}\right)$ in compound 3

\begin{tabular}{llll}
\hline Cu1-O14 & $1.916(2)$ & Cu3-O12 & $1.917(2)$ \\
Cu1-O15 & $1.919(2)$ & Cu3-O10 & $1.933(2)$ \\
Cu1-O1 & $2.005(2)$ & Cu3-O5 & $2.018(2)$ \\
Cu1-N1 & $2.028(3)$ & Cu3-N3 & $2.026(3)$ \\
Cu2-N2 & $1.979(3)$ & Cu2-O11 & $2.050(2)$ \\
Cu2-O6 & $1.981(2)$ & Cu2-O16 & $2.110(2)$ \\
Cu2-O7 & $1.997(2)$ & & \\
O14-Cu1-O15 & $174.70(9)$ & O12-Cu3-O10 & $165.67(9)$ \\
O14-Cu1-O1 & $89.86(9)$ & O12-Cu3-O5 & $91.00(9)$ \\
O15-Cu1-O1 & $91.77(9)$ & O10-Cu3-O5 & $90.49(9)$ \\
O14-Cu1-N1 & $89.01(10)$ & O12-Cu3-N3 & $89.13(10)$ \\
O15-Cu1-N1 & $88.37(10)$ & O10-Cu3-N3 & $87.42(10)$ \\
O1-Cu1-N1 & $168.35(9)$ & O5-Cu3-N3 & $171.93(9)$ \\
N2-Cu2-O6 & $176.24(10)$ & O7-Cu2-O11 & $128.77(9)$ \\
N2-Cu2-O7 & $93.16(10)$ & N2-Cu2-O16 & $89.05(9)$ \\
O6-Cu2-O7 & $89.92(8)$ & O6-Cu2-O16 & $87.31(8)$ \\
N2-Cu2-O11 & $88.69(10)$ & O7-Cu2-O16 & $130.73(9)$ \\
O6-Cu2-O11 & $91.07(8)$ & O11-Cu2-O16 & $100.47(8)$ \\
\hline
\end{tabular}

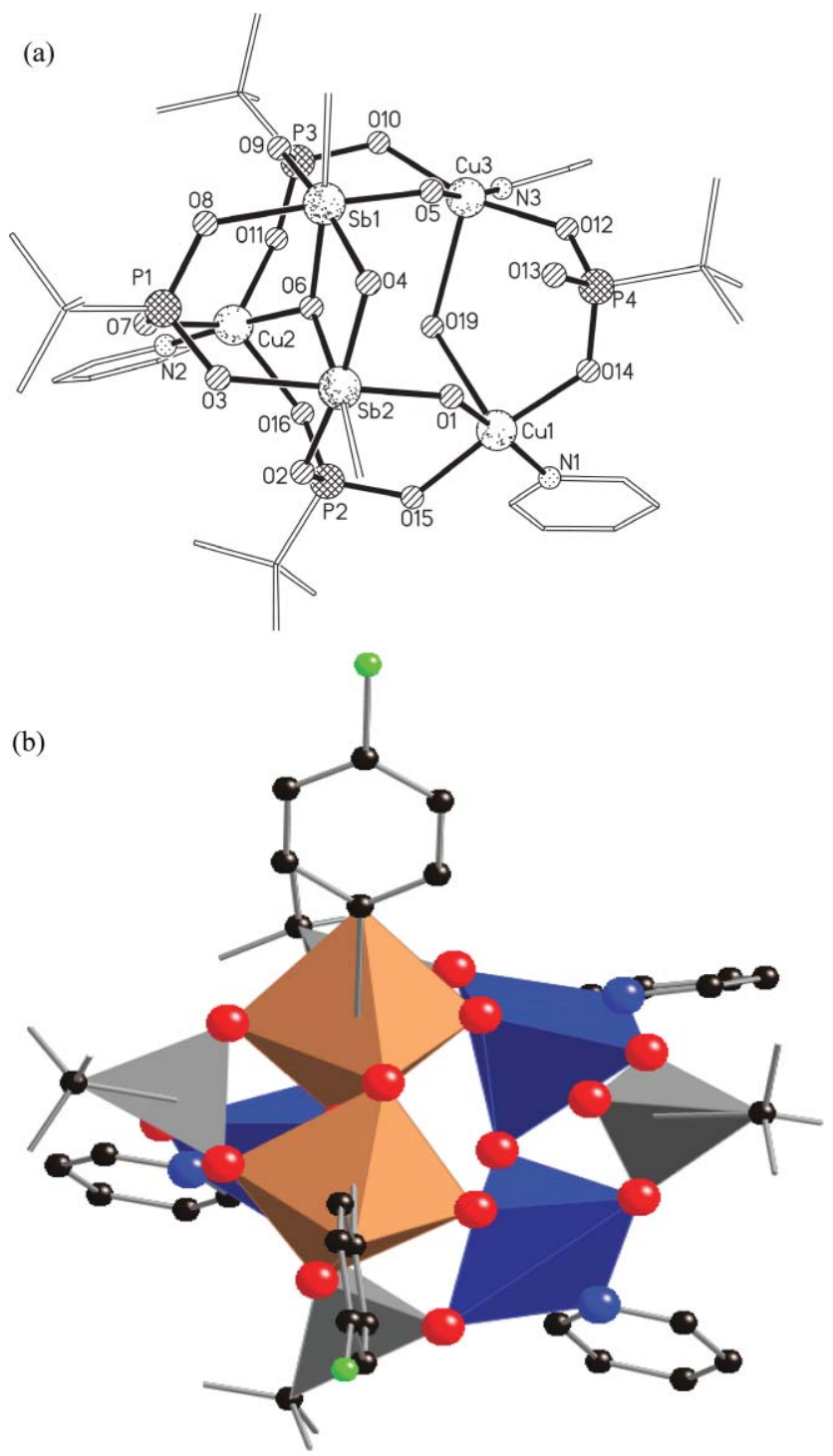

Fig. 3 The structure of $\mathbf{3}$ in the crystal shown (a) as a ball-and-stick view (aryl group on $\mathrm{Sb}$ excluded for clarity), and (b) as a polyhedral view. Colour scheme as Fig. 2, plus N, blue spheres.

crystals of $\mathbf{2}$ were removed. The low yield of $\mathbf{4}$ prevented magnetic characterisation.

The structure of 4 (Fig. 4) contains five $\mathrm{Cu}$ and four $\mathrm{Sb}$ centres connected through six phosphonates, two acetates and four methoxides. The copper centres make a bow-tie consisting of two triangles ( $\mathrm{Cu} 1, \mathrm{Cu} 2$ and $\mathrm{Cu} 3$, and $\mathrm{Cu} 3, \mathrm{Cu} 4$ and $\mathrm{Cu} 5$ respectively) connected at $\mathrm{Cu} 3$. There is one $\mathrm{Sb}$ centre above and one below the plane of each triangle. Thus Sb1 and Sb2 lie above and below the first triangle while $\mathrm{Sb} 3$ and $\mathrm{Sb} 4$ are associated with the second triangle.

Four of the copper sites, $\mathrm{Cu} 1, \mathrm{Cu} 2, \mathrm{Cu} 4$ and $\mathrm{Cu} 5$, have square pyramidal geometries, while $\mathrm{Cu} 3$ is square planar. The $\mathrm{Cu} 1$ centre has one $\mu_{3}$-oxide (O16), a $\mu_{2}$-methoxide (O17), an oxygen from an acetate $(\mathrm{O} 10)$ and an oxygen $(\mathrm{O} 9)$ from a phosphonate at equatorial positions of the square pyramid, while a further phosphonate oxygen (O31) occupies the equatorial position. All the equatorial bond distances are around $1.95 \AA$, while the axial Cu1-O31 bond distance is 2.390(4) $\AA$. The O10-Cu1-O31 bond 


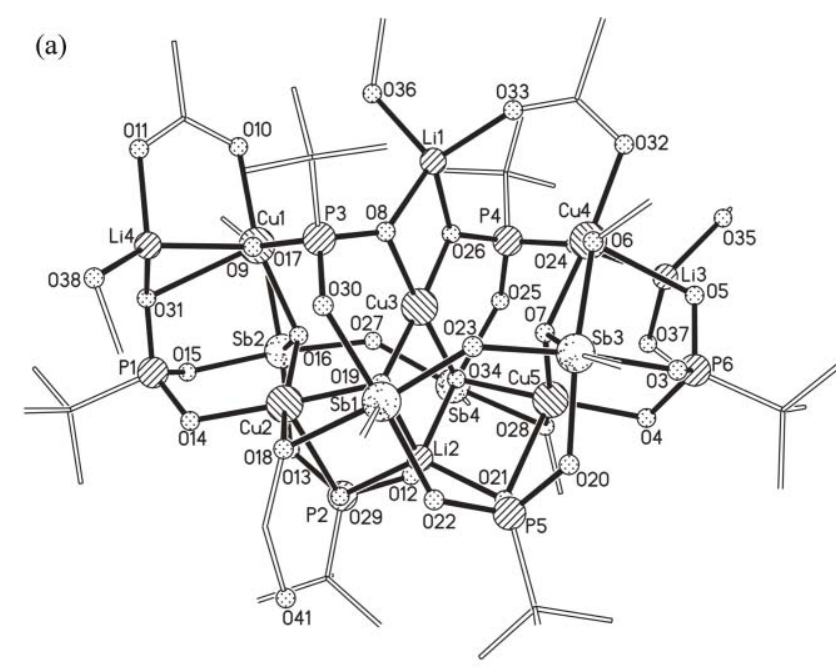

Table 5 Selected bond lengths $(\AA)$ and angles $\left({ }^{\circ}\right)$ in compound 4

\begin{tabular}{|c|c|c|c|}
\hline $\mathrm{Cu} 1-\mathrm{O} 10$ & $1.950(4)$ & $\mathrm{Cu} 4-\mathrm{O} 32$ & $1.935(4)$ \\
\hline $\mathrm{Cu} 1-\mathrm{O} 16$ & $1.953(3)$ & $\mathrm{Cu} 4-\mathrm{O} 7$ & $1.955(3)$ \\
\hline $\mathrm{Cu} 1-\mathrm{O} 17$ & $1.970(4)$ & $\mathrm{Cu} 4-\mathrm{O} 6$ & $1.984(4)$ \\
\hline $\mathrm{Cu} 1-\mathrm{O} 9$ & $1.981(4)$ & $\mathrm{Cu} 4-\mathrm{O} 24$ & $1.991(4)$ \\
\hline $\mathrm{Cu} 1-\mathrm{O} 31$ & $2.390(4)$ & $\mathrm{Cu} 4-\mathrm{O} 5$ & $2.385(4)$ \\
\hline $\mathrm{Cu} 2-\mathrm{O} 14$ & $1.907(3)$ & $\mathrm{Cu} 5-\mathrm{O} 4$ & $1.912(3)$ \\
\hline $\mathrm{Cu} 2-\mathrm{O} 16$ & $1.948(4)$ & $\mathrm{Cu} 5-\mathrm{O} 34$ & $1.950(3)$ \\
\hline $\mathrm{Cu} 2-\mathrm{O} 19$ & $1.964(3)$ & $\mathrm{Cu} 5-\mathrm{O} 7$ & $1.951(3)$ \\
\hline $\mathrm{Cu} 2-\mathrm{O} 18$ & $2.003(4)$ & $\mathrm{Cu} 5-\mathrm{O} 28$ & $2.013(3)$ \\
\hline $\mathrm{Cu} 2-\mathrm{O} 29$ & $2.401(3)$ & $\mathrm{Cu} 5-\mathrm{O} 21$ & $2.348(4)$ \\
\hline Cu3-O19 & $1.921(3)$ & $\mathrm{Cu} 3-\mathrm{O} 26$ & $1.969(4)$ \\
\hline $\mathrm{Cu} 3-\mathrm{O} 34$ & $1.939(3)$ & $\mathrm{Cu} 3-\mathrm{O} 8$ & $1.979(3)$ \\
\hline Li1-O33 & $1.884(13)$ & Li3-O35 & $1.886(15)$ \\
\hline Li1-O8 & $1.922(12)$ & Li3-O5 & $1.919(11)$ \\
\hline Li1-O36 & $1.933(12)$ & Li3-O37 & $1.953(13)$ \\
\hline Li1-O26 & $1.990(12)$ & Li3-O24 & $1.978(11)$ \\
\hline Li2-O29 & $1.849(9)$ & Li4-O38 & $1.879(12)$ \\
\hline Li2-O21 & $1.868(9)$ & Li4-O31 & $1.915(12)$ \\
\hline Li2-O19 & $1.967(9)$ & Li4-O11 & $1.957(12)$ \\
\hline Li2-O34 & $1.970(9)$ & Li4-O9 & $1.969(11)$ \\
\hline O10-Cu1-O16 & $163.97(16)$ & $\mathrm{O} 32-\mathrm{Cu} 4-\mathrm{O} 7$ & $169.70(17)$ \\
\hline O10-Cu1-O17 & $92.53(17)$ & O32-Cu4-O6 & $92.10(18)$ \\
\hline O16-Cu1-O17 & $79.29(15)$ & $\mathrm{O} 7-\mathrm{Cu} 4-\mathrm{O} 6$ & $78.93(14)$ \\
\hline O10-Cu1-O9 & $92.62(16)$ & $\mathrm{O} 32-\mathrm{Cu} 4-\mathrm{O} 24$ & $92.32(17)$ \\
\hline O16-Cu1-O9 & $95.48(15)$ & $\mathrm{O} 7-\mathrm{Cu} 4-\mathrm{O} 24$ & $96.32(14)$ \\
\hline O17-Cu1-O9 & $174.77(15)$ & O6-Cu4-O24 & $174.24(15)$ \\
\hline O10-Cu1-O31 & $104.77(16)$ & $\mathrm{O} 32-\mathrm{Cu} 4-\mathrm{O} 5$ & $95.74(17)$ \\
\hline O16-Cu1-O31 & $90.03(14)$ & $\mathrm{O} 7-\mathrm{Cu} 4-\mathrm{O} 5$ & $91.19(14)$ \\
\hline O17-Cu1-O31 & $97.24(15)$ & O6-Cu4-O5 & $102.47(15)$ \\
\hline O9-Cu1-O31 & $82.34(15)$ & $\mathrm{O} 24-\mathrm{Cu} 4-\mathrm{O} 5$ & $80.76(14)$ \\
\hline O14-Cu2-O16 & $94.18(15)$ & $\mathrm{O} 4-\mathrm{Cu} 5-\mathrm{O} 34$ & $174.78(15)$ \\
\hline O14-Cu2-O19 & $175.15(15)$ & O4-Cu5-O7 & $94.48(15)$ \\
\hline O16-Cu2-O19 & $88.23(14)$ & O34-Cu5-O7 & 88.51(14) \\
\hline O14-Cu2-O18 & $98.68(15)$ & $\mathrm{O} 4-\mathrm{Cu} 5-\mathrm{O} 28$ & $96.84(14)$ \\
\hline O16-Cu2-O18 & $158.64(15)$ & $\mathrm{O} 34-\mathrm{Cu} 5-\mathrm{O} 28$ & $78.78(14)$ \\
\hline O19-Cu2-O18 & $77.80(14)$ & $\mathrm{O} 7-\mathrm{Cu} 5-\mathrm{O} 28$ & $154.91(15)$ \\
\hline $\mathrm{O} 14-\mathrm{Cu} 2-\mathrm{O} 29$ & $100.67(14)$ & $\mathrm{O} 4-\mathrm{Cu} 5-\mathrm{O} 21$ & $99.33(15)$ \\
\hline $\mathrm{O} 16-\mathrm{Cu} 2-\mathrm{O} 29$ & $96.00(13)$ & $\mathrm{O} 34-\mathrm{Cu} 5-\mathrm{O} 21$ & $84.39(13)$ \\
\hline $\mathrm{O} 19-\mathrm{Cu} 2-\mathrm{O} 29$ & $83.23(13)$ & $\mathrm{O} 7-\mathrm{Cu} 5-\mathrm{O} 21$ & $99.00(13)$ \\
\hline $\mathrm{O} 18-\mathrm{Cu} 2-\mathrm{O} 29$ & $98.28(14)$ & $\mathrm{O} 28-\mathrm{Cu} 5-\mathrm{O} 21$ & $101.15(14)$ \\
\hline O19-Cu3-O34 & $84.73(14)$ & O19-Cu3-O8 & $93.52(15)$ \\
\hline $\mathrm{O} 19-\mathrm{Cu} 3-\mathrm{O} 26$ & $175.35(15)$ & O34-Cu3-O8 & $174.93(14)$ \\
\hline $\mathrm{O} 34-\mathrm{Cu} 3-\mathrm{O} 26$ & $94.17(15)$ & $\mathrm{O} 26-\mathrm{Cu} 3-\mathrm{O} 8$ & $87.95(15)$ \\
\hline $\mathrm{Cu} 5-\mathrm{O} 7-\mathrm{Cu} 4$ & $116.96(17)$ & $\mathrm{Cu} 3-\mathrm{O} 19-\mathrm{Cu} 2$ & $111.67(16)$ \\
\hline $\mathrm{Cu} 2-\mathrm{O} 16-\mathrm{Cu} 1$ & $116.02(18)$ & $\mathrm{Cu} 3-\mathrm{O} 34-\mathrm{Cu} 5$ & $110.29(15)$ \\
\hline
\end{tabular}

Fig. 4 The structure of $\mathbf{4}$ in the crystal shown (a) as a ball-and-stick view (aryl group on $\mathrm{Sb}$ excluded for clarity), and (b) as a polyhedral view. Colour scheme as Fig. 3, plus Li, light blue spheres.

angle is $104.8(2)^{\circ}$, causing a distortion in the square pyramidal geometry. The coordination environment around $\mathrm{Cu} 4$ involves a similar set of donor atoms.

The $\mathrm{Cu} 2$ centre has a $\mu_{3}$-oxide (O16), a $\mu_{4}$-oxide (O19), a $\mu_{2}-$ methoxide (O18) and an oxygen (O14) from a phosphonate at the equatorial positions of the square pyramid, while a further oxygen donor $(\mathrm{O} 29)$ from another phosphonate at the axial site. All the equatorial bond distances are in the range of 1.9-2.0 $\AA$, while axial Cu2-O29 bond distance is 2.401(3) $\AA$. The O14-Cu2-O18 bond angle is $98.7(2)^{\circ}$ which is the chief distortion in the square pyramidal geometry. The coordination environment around $\mathrm{Cu} 5$ involves a similar set of donor atoms to $\mathrm{Cu} 2$.

The square planar $\mathrm{Cu} 3$ centre is connected to two $\mu_{4}$-oxides (O19 and $\mathrm{O} 34)$ and two phosphonate oxygens $(\mathrm{O} 8$ and $\mathrm{O} 26)$. The $\mathrm{Cu} 3-$ O bond distances are in the range of 1.92-1.97 $\AA$ and all the bond angles are regular. There is a clear trend in the $\mathrm{Sb}-\mathrm{O}$ bond lengths, with bonds involving oxides falling in the range 1.923-1.961(4) $\AA$, while where phosphonates are involved the $\mathrm{Sb}-\mathrm{O}$ bonds fall in the range 2.006-2.123(4) $\AA$. Selected bond distances and bond angles for compound $\mathbf{4}$ are shown in Table 5.

There are four Li centres, each is four coordinate and two of these coordination sites are occupied by oxygen donors from phosphonates, while occupation of the other sites vary. In case of Lil and Li4, the other two sites are occupied by an oxygen from methanol and a O-atom from acetate. For Li2 centre the two additional sites are occupied by two $\mu_{4}$-oxides, while for Li3 two methanol molecules occupy these sites.

The phosphorous centres occupy the triangular faces made by $\mathrm{Sb}$ and $\mathrm{Cu}$ centres, and then bind further to the external $\mathrm{Li}$ atoms. Four of the phosphonates (those involving P1, P2, P5 and P6) have a bonding mode of 4.211, while final two phosphonates (involving P3 and P4) have a 5.221 mode. Each phosphonate, with a bonding mode 4.211 , contain one oxygen donor bridging between a $\mathrm{Li}$ and a $\mathrm{Cu}$ centre while the other two oxygen donors coordinate to either a $\mathrm{Sb}$ or $\mathrm{Cu}$ centre. Similarly each phosphonate with bonding mode 5.221, has two oxygen donors bridging between $\mathrm{Li}$ and $\mathrm{Cu}$ centres and one oxygen donor coordinating to an antimony.

Compound $\mathbf{5}$ was obtained by the reaction of $\mathbf{1}$ with copper acetate in $\mathrm{MeCN}$ under solvothermal conditions, using 2,6lutidine as base. The crystals of $\mathbf{5}$ appeared by slow cooling of the 
$\mathrm{MeCN}$ solution. The structure is centro-symmetric and contains two $\mathrm{Sb}$ and eight $\mathrm{Cu}$ centres connected through six phosphonates (Fig. 5). The core of the structure is an edge-sharing oxo-centred tetrahedron $\mathrm{Cu}_{4} \mathrm{Sb}_{2}\left(\mu_{4}-\mathrm{O}\right)_{2} ; \mathrm{Cu} 2$ and $\mathrm{Cu} 2 \mathrm{a}$ are in the shared edge, with $\mathrm{Cu} 3, \mathrm{Cu} 3 \mathrm{a}, \mathrm{Sb} 1$ and $\mathrm{Sb} 1 \mathrm{a}$ on the exterior vertices. The $\mu_{4}$ oxides are $\mathrm{O} 15$ and O15a. The three crystallographically unique phosphonates all adopt the 3.111 mode, and bridge edges of this core polyhedron and then on to the additional copper sites. The phosphonate containing P1 bridges from Sb1 to Cu3a (Fig. 5), and then on to $\mathrm{Cu} 1$. The phosphonate containing $\mathrm{P} 2$ bridges from $\mathrm{Sb} 1$ to $\mathrm{Cu} 2$, and then to $\mathrm{Cu} 1$, while the P3-phosphonate bridges $\mathrm{Sb} 1$ to $\mathrm{Cu} 2 \mathrm{a}$ and then on to $\mathrm{Cu} 4$. There is a $\mu_{3}$-oxide between $\mathrm{Sb} 1$, $\mathrm{Cu} 3$ and $\mathrm{Cu} 4$ and there is also a 2.11 bridging acetate between $\mathrm{Cu} 4$ and $\mathrm{Cu} 3$. The coordination site of $\mathrm{Cu} 1$ is completed by a chelating acetate while that of $\mathrm{Cu} 4$ has a terminal lutidine attached.

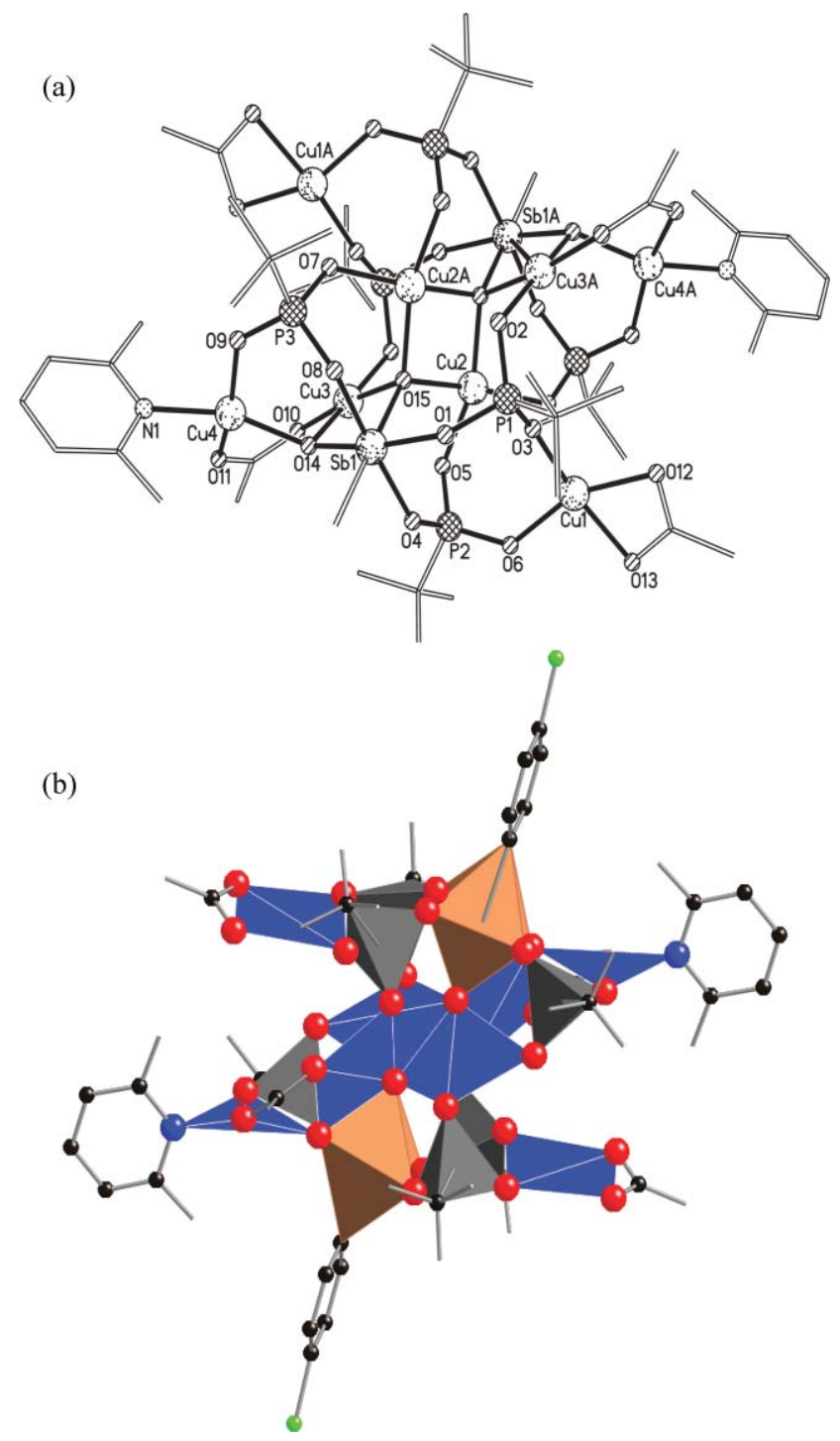

Fig. 5 The structure of 5 in the crystal shown (a) as a ball-and-stick view (aryl group on $\mathrm{Sb}$ excluded for clarity), and (b) as a polyhedral view. Colour scheme as Fig. 3.

All the $\mathrm{Cu}$ centres are approximately square planar. The $\mathrm{Cu} 1$ centre is coordinated to two $\mathrm{O}$-donors from phosphonates $(\mathrm{O} 3$ and $\mathrm{O} 6)$ and the chelating acetate $(\mathrm{O} 12, \mathrm{O} 13)$. The chief distortion from
Table 6 Selected bond lengths $(\AA)$ and angles $\left({ }^{\circ}\right)$ in compound 5

\begin{tabular}{llll}
\hline $\mathrm{Cu} 1-\mathrm{O} 6$ & $1.898(2)$ & $\mathrm{Cu} 3-\mathrm{O} 14$ & $1.928(2)$ \\
$\mathrm{Cu} 1-\mathrm{O} 3$ & $1.908(2)$ & $\mathrm{Cu} 3-\mathrm{O} 10$ & $1.929(2)$ \\
$\mathrm{Cu} 1-\mathrm{O} 12$ & $1.990(2)$ & $\mathrm{Cu} 3-\mathrm{O} 2$ & $1.932(2)$ \\
$\mathrm{Cu} 1-\mathrm{O} 13$ & $2.007(3)$ & $\mathrm{Cu} 3-\mathrm{O} 15$ & $2.000(2)$ \\
$\mathrm{Cu} 2-\mathrm{O} 5$ & $1.915(2)$ & $\mathrm{Cu} 4-\mathrm{O} 14$ & $1.912(2)$ \\
$\mathrm{Cu} 2-\mathrm{O} 7$ & $1.939(2)$ & $\mathrm{Cu} 4-\mathrm{O} 9$ & $1.918(3)$ \\
$\mathrm{Cu} 2-\mathrm{O} 15$ & $1.958(2)$ & $\mathrm{Cu} 4-\mathrm{O} 11$ & $1.941(2)$ \\
$\mathrm{Cu} 2-\mathrm{O} 15$ & $2.008(2)$ & $\mathrm{Cu} 4-\mathrm{N} 1$ & $1.973(2)$ \\
O6-Cu1-O3 & $98.49(10)$ & O14-Cu3-O10 & $93.22(9)$ \\
O6-Cu1-O12 & $157.45(11)$ & O14-Cu3-O2 & $171.17(9)$ \\
O3-Cu1-O12 & $99.36(10)$ & O10-Cu3-O2 & $95.17(9)$ \\
O6-Cu1-O13 & $93.58(10)$ & O14-Cu3-O15 & $80.94(8)$ \\
O3-Cu1-O13 & $159.64(10)$ & O10-Cu3-O15 & $172.36(9)$ \\
O12-Cu1-O13 & $65.57(11)$ & O2-Cu3-O15 & $90.93(9)$ \\
O5-Cu2-O7 & $95.19(10)$ & O14-Cu4-O9 & $99.40(9)$ \\
O5-Cu2-O15 & $160.71(8)$ & O14-Cu4-O11 & $89.33(10)$ \\
O7-Cu2-O15 & $99.18(9)$ & O9-Cu4-O11 & $161.04(11)$ \\
O5-Cu2-O15 & $87.95(9)$ & O14-Cu4-N1 & $159.86(10)$ \\
O7-Cu2-O15 & $161.71(9)$ & O9-Cu4-N1 & $87.28(11)$ \\
O15-Cu2-O15 & $82.44(9)$ & O11-Cu4-N1 & $90.20(11)$ \\
Cu4-O14-Cu3 & $107.15(10)$ & Cu2-O15-Cu2a & $97.56(9)$ \\
Cu2-O15-Cu3a & $114.91(10)$ & Cu3-O15-Cu2 & $95.91(9)$ \\
\hline
\end{tabular}

square planar geometry is due to the small O12-Cu1-O13 angle $\left(65^{\circ}\right)$ due to the bite angle of acetate. The $\mathrm{Cu} 2$ site is coordinated to two $\mu_{4}$-oxides (O15 and $\left.\mathrm{O} 15 \mathrm{a}\right)$ and two phosphonate oxygens (O5 and $\mathrm{O} 7 \mathrm{a})$. The $\mathrm{Cu} 3$ centre is coordinated to a $\mu_{4}$-oxide $(\mathrm{O} 15)$, a $\mu_{3}$-oxide $(\mathrm{O} 14)$, one oxygen donor $(\mathrm{O} 2)$ from a phosphonate and one oxygen donor $(\mathrm{O} 10)$ from acetate. Finally, $\mathrm{Cu} 4$ is coordinated to a $\mu_{3}$-oxide (O14), one oxygen donor (O9) from a phosphonate, one oxygen donor $(\mathrm{O} 11)$ from acetate and a lutidine. The $\mathrm{Cu}-\mathrm{O}$ bond distances are not exceptional. The distances between the $\mathrm{Cu}$ centres connected through a $\mu_{4}$-oxide $(\mathrm{O} 15)$ are in the range of 2.97-3.34 $\AA$. The $\mathrm{Sb}-\mathrm{O}$ bond involving the $\mu_{3}$-oxide is 1.962(2) $\AA$, while the other $\mathrm{Sb}-\mathrm{O}$ bonds in the structure fall in the range 1.998-2.022(2) A. Selected bond distances and bond angles for compound $\mathbf{5}$ are shown in Table 6.

In each case it is necessary to make compound $\mathbf{1}$ prior to reacting with the copper salt. If the components that make 1 are added separately to a copper salt, then insoluble and uncharacterisable materials form, which we believe are polymeric copper phosphonates. The condensation reaction to give 1 restricts the formation of these polymeric materials.

\section{Magnetic studies}

DC magnetic studies were carried out on polycrystalline samples of 2, 3 and 5, in the temperature range 2-300 K. The temperature dependence of the magnetic susceptibility of 2 is shown as a $\chi_{\mathrm{m}} T v s$. $T$ plot $\left(\chi_{\mathrm{m}}=\right.$ molar magnetic susceptibility) in Fig. 6 . The product $\chi_{\mathrm{m}} T$ is $1.42 \mathrm{~cm}^{3} \mathrm{~K} \mathrm{~mol}^{-1}$ at room temperature and decreases rapidly upon cooling to approach $0.012 \mathrm{~cm}^{3} \mathrm{~K} \mathrm{~mol}^{-1}$ at $1.8 \mathrm{~K}$. In addition, the magnetic susceptibility curve shows a maximum at $c a .145 \mathrm{~K}$, which is the signature of dominant antiferromagnetic exchange between metal centers leading to a $\mathrm{S}=0$ ground state. The nonzero value of the $\chi_{\mathrm{m}} T$ at low temperatures is probably due to both temperature independent paramagnetism (TIP) and a small amount of paramagnetic impurity (approximately 1.5\%). Similar behaviour has been reported for other $\mathrm{Cu}$ (II) tetramers. ${ }^{14}$

In compound $\mathbf{2}$ the four copper centres are arranged in a rhombus with the super-exchange paths along alternate edges of the rhombus very different. For two edges the exchange is via 


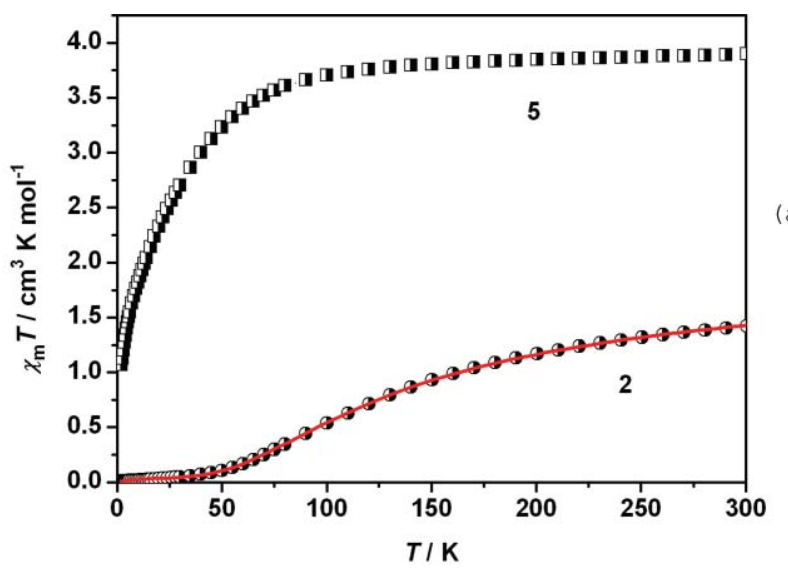

(a)

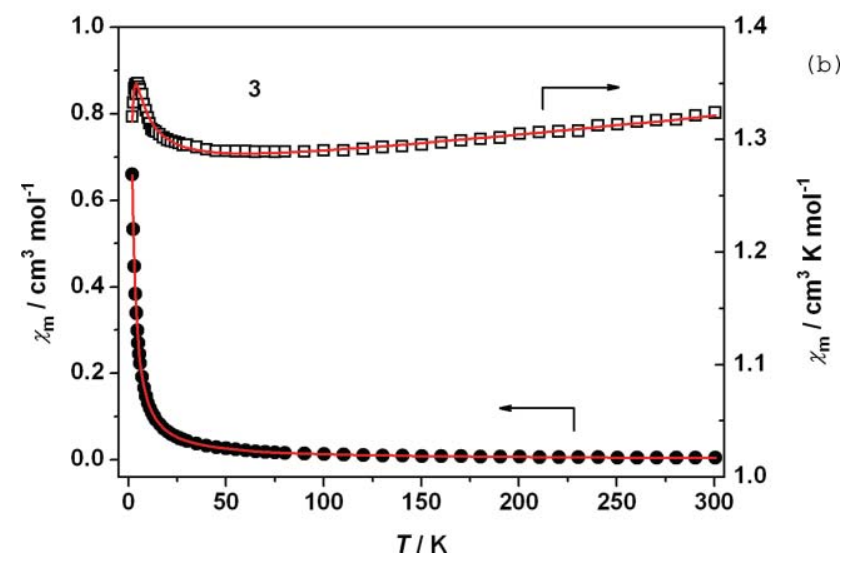

Fig. 6 a) Plots of $\chi_{\mathrm{m}} T v s . T$ for compounds $\mathbf{2}$ and $\mathbf{5}$, with best fit of the data for 2 shown as a solid line; b) Plots of $\chi_{\mathrm{m}}$ and $\chi_{\mathrm{m}} T v s . T$ for compound 3 with the best fit of the data shown as a solid line.

two O-atoms from phosphonates and a 2.11-bridging carboxylate, while on the other two edges the bridging is via a $\mu_{3}$-oxide, which also binds to a $\mathrm{Sb}$ centre.

Attempts to simulate the magnetic data of $\mathbf{2}$ on the base of the general spin Hamiltonian $H=-J_{\mathrm{a}}\left(S_{1} S_{2}+S_{3} S_{4}\right)-J_{\mathrm{b}}\left(S_{2} S_{3}+\right.$ $\left.S_{1} S_{4}\right)-J_{\mathrm{c}}\left(S_{1} S_{3}+S_{2} S_{4}\right)$ with $S_{1}=S_{2}=S_{3}=S_{4}=1 / 2$ failed, because the three exchange couplings are correlated and could not be determined unambiguously. Setting any one of the exchange coupling constants to zero also failed to fit the data. However, with $J_{\mathrm{b}}$ and $J_{\mathrm{c}}$ fixed to zero, and taking into account a small percentage of paramagnetic impurity ( $c a .1 .2 \%)$ - assumed to be a copper(II) monomer with a similar $g$ factor - the data could be fitted reasonably well giving $J_{\mathrm{a}}=-164.2 \mathrm{~cm}^{-1}$ and $g=2.17$; this $g$ value is very close to the value of 2.173 determined by EPR spectroscopy. This suggests that the magnetic exchange along one edge of the rhombus is much larger than any other exchange interaction present, so we assumed that the magnetic behaviour of $\mathbf{2}$ could also be modeled as two weakly-interacting copper(II) dimers, and used eqn (1) to fit the data.

$$
\chi_{m}^{C u_{4}}=\frac{4 N \beta^{2} g^{2}}{k_{B}(T-\theta)} \frac{1}{3+\exp \left(-J / k_{B} T\right)}(1-\rho)+\rho \frac{N \beta^{2} g^{2}}{k_{B} T}+T I P
$$

A Weiss constant, $\theta$, was included to take into account possible exchange interaction between dimers. The best fit was obtained with $g=2.166, J=-165.4 \mathrm{~cm}^{-1}, \theta=-1.93 \mathrm{~K}$, with the paramagnetic impurity fraction $\rho=0.015$, TIP $=240 \times 10^{-6} \mathrm{~cm}^{3} \mathrm{~mol}^{-1}$ and $R=$ $1.0 \times 10^{5}\left(\mathrm{R}\right.$ is the reliability factor defined as $\sum_{\mathrm{i}}\left[\left(\chi_{\mathrm{m}} T\right)_{\text {obs }}(\mathrm{i})-\right.$ $\left.\left.\left(\chi_{\mathrm{m}} T\right)_{\text {calc }}(\mathrm{i})\right]^{2} / \sum_{\mathrm{i}}\left[\left(\chi_{\mathrm{m}} T\right)_{\text {obs }}(\mathrm{i})\right]^{2}\right)$.

The fit is excellent (solid line, Fig. 6a), but this fit does not define the edge of the rhombus that corresponds to the stronger antiferromagnetic exchange. Taking into account the structure of this compound, it is reasonably to assume that the stronger magnetic exchange occurs via the $\mu_{3}$ oxide bridge as the bridging angle at this oxygen is most obtuse $\left(\mathrm{Cu} 1-\mathrm{O} 5-\mathrm{Cu} 2=135^{\circ}\right)$. The other edge is bridged by an acetate ligand, and two $\mu_{2}$-oxygen atoms from phosphonate. The position of these two phosphonate oxygens is such that they are in an axial position on one $\mathrm{Cu}$ and an equatorial position on the second; such bridging makes the magnetic orbitals orthogonal and would lead to a weak, and possibly weakly ferromagnetic, exchange interaction. ${ }^{15}$

For compound 3 the room temperature value of $\chi_{\mathrm{m}} T$ is $1.32 \mathrm{~cm}^{3} \mathrm{~K} \mathrm{~mol}^{-1}$, above the calculated value of $1.24 \mathrm{~cm}^{3} \mathrm{~K}$ $\mathrm{mol}^{-1}$ for three $\mathrm{S}=1 / 2$ centers with $g=2.1$ (Fig. 6b). The value declines slowly on cooling to reach $1.29 \mathrm{~cm}^{3} \mathrm{~K} \mathrm{~mol}^{-1}$ at $50 \mathrm{~K}$, before increasing to $1.35 \mathrm{~cm}^{3} \mathrm{~K} \mathrm{~mol}^{-1}$ at $5 \mathrm{~K}$. Below $5 \mathrm{~K}$, $\chi_{\mathrm{m}} T$ decreases again and reaches $1.32 \mathrm{~cm}^{3} \mathrm{~K} \mathrm{~mol}^{-1}$ at $2 \mathrm{~K}$. Close inspection of the structure of $\mathbf{3}$ shows that the $\mathrm{Cu} 2$ center is well isolated from the other two coppers, $\mathrm{Cu} 1$ and $\mathrm{Cu} 3$, so that we can model the magnetic behaviour of $\mathbf{3}$ as the sum of contributions of a $\mathrm{Cu}$ (II) dimer and a $\mathrm{Cu}$ (II) monomer, using eqn (2). A Weiss constant $\theta$ was incorporated into analysis to take account of weak intermolecular interactions that occur at low temperatures. Any interaction between the mono-copper centre and the dimer is also contributing to this number. The best fit of $\chi_{\mathrm{m}}$, as well as of $\chi_{\mathrm{m}} T$, using eqn (2), gave $g=2.12, J=5.15 \mathrm{~cm}^{-1}, \theta=-0.3 \mathrm{~K}$, with $R=$ $6.58 \times 10^{-6}$ and TIP $=180 \times 10^{-6} \mathrm{~cm}^{3} \mathrm{~K} \mathrm{~mol}^{-1}$.

$$
\chi_{m}^{C u_{3}}=\frac{2 N \beta^{2} g^{2}}{k_{B}(T-\theta)} \frac{1}{3+\exp \left(-J / k_{B} T\right)}+\frac{N \beta^{2} g^{2}}{4 k_{B}(T-\theta)}+T I P
$$

The results show that the magnetic interaction between $\mathrm{Cu} 1$ and $\mathrm{Cu} 3$ is ferromagnetic $\left(J=5.15 \mathrm{~cm}^{-1}\right)$, and this can be rationalized as arising from the orthogonality of the magnetic orbitals of square-planar copper(II) centers $\left(\mathrm{d}_{x 2-y 2}\right.$ orbitals) and bridging oxygen atoms (p orbitals) along the $\mathrm{Cu} 1-\mathrm{O} 19-\mathrm{Cu} 3$ connection. The second bridging ligand that connect $\mathrm{Cu} 1$ and $\mathrm{Cu} 3$ is a phosphonate group disposed in equatorial-equatorial position with respect to the adjacent copper ions. This ligand may promote antiferromagnetic exchange, but exchange coupling through phosphonate ligands is normally found to be small. ${ }^{6}$

The magnetic susceptibility data of $\mathbf{5}$ are plotted as $\chi_{\mathrm{m}} T$ against $T$ in Fig. 6a. The room temperature $\chi_{\mathrm{m}} T$ value of $3.89 \mathrm{~cm}^{3} \mathrm{~K}$ $\mathrm{mol}^{-1}$ indicates that any interaction between the metal centres is weak. Below $100 \mathrm{~K}, \chi_{\mathrm{m}} T$ falls steadily which suggests that the predominant interactions in the cage are anti-ferromagnetic. The value of $\chi_{\mathrm{m}} T$ at $2 \mathrm{~K}$ is $1.07 \mathrm{~cm}^{3} \mathrm{~K} \mathrm{~mol}^{-1} ; \chi_{\mathrm{m}} T$ is still falling it seems likely that the ground state of the cage is $S=0$. Given the low symmetry of the cage with many possible exchange paths, no attempt to fit this data was made.

\section{Conclusion}

Compound $\mathbf{1}$ is clearly a pro-ligand that can be combined with copper(II) to produce new polymetallic complexes, with 
the nuclearity of the complex dependent on the base used in the reaction. Initial magnetic studies show anti-ferromagnetic or weak ferromagnetic exchange between the spin centres in these compounds.

\section{Acknowledgements}

SA thanks the Higher Education Commission of Pakistan for a studentship, and REPW thanks the Royal Society for a Wolfson Merit Award. This work was supported by the EPSRC(UK).

\section{References}

1 (a) V. Chandrasekhar and S. Kingsley, S., Angew. Chem., Int. Ed., 2000, 39, 2320-2322; (b) V. Chandrasekhar, L. Nagarajan, R. Clérac, S. Ghosh and S. Verma, Inorg. Chem., 2008, 47, 1067-1073; (c) V. Chandrasekhar, P. Sasikumar, R. Boomishankar and G. Anantharaman, Inorg. Chem., 2006, 45, 3344-3351; (d) V. Chandrasekhar, L. Nagarajan, R. Clérac, S. Ghosh, T. Senapati and S. Verma, Inorg. Chem., 2008, 47, 5347-5354.

2 (a) E. K. Brechin, R. A. Coxall, A. Parkin, S. Parsons, P. A. Tasker and R. E. P. Winpenny, Angew. Chem., Int. Ed., 2001, 40, 2700-2703; (b) S. Langley, M. Helliwell, R. Sessoli, S. J. Teat and R. E. P. Winpenny, Inorg. Chem., 2008, 47, 497-507; (c) S. Langley, M. Helliwell, R. Sessoli, S. J. Teat and R. E. P. Winpenny, Dalton Trans., 2009, 3102-3110.

3 B. A. Breeze, M. Shanmugam, F. Tuna and R. E. P. Winpenny, Chem. Commun., 2007, 5185-5187.

4 (a) S. Khanra, M. Kloth, H. Mansaray, C. A. Muryn, F. Tuna, E. C. Sañudo, M. Helliwell, E. J. L. McInnes and R. E. P. Winpenny, Angew. Chem., Int. Ed., 2007, 46, 5568-5571; (b) S. Khanra, M. Helliwell, F. Tuna, E. J. L. McInnes and R. E. P. Winpenny, J. Mol. Struct., 2008, 890, 157-162.

5 (a) E. I. Tolis, M. Helliwell, S. Langley, J. Raftery and R. E. P. Winpenny, Angew. Chem., Int. Ed., 2003, 42, 3804; (b) S. Khanra, S. Konar, A. Clearfield, M. Helliwell, E. J. L. McInnes, E. Tolis, F. Tuna and R. E. P. Winpenny, Inorg. Chem., 2009, 48, 5338-5349; (c) S. Khanra, M. Helliwell, F. Tuna, E. J. L. McInnes and R. E. P. Winpenny, Dalton Trans., 2009, 6166-6174.
6 (a) M. Maheswaran, G. Chastanet, S. J. Teat, T. Mallah, R. Sessoli, W. Wernsdorfer and R. E. P. Winpenny, Angew. Chem., Int. Ed., 2005, 44, 5044-5048; (b) M. Shanmugam, G. Chastanet, T. Mallah, R. Sessoli, S. J. Teat, G. A. Timco and R. E. P. Winpenny, Chem.-Eur. J., 2006, 12, 8777-8785; (c) M. Shanmugam, M. Shanmugam, G. Chastanet, R. Sessoli, T. Mallah, W. Wernsdorfer and R. E. P. Winpenny, J. Mater. Chem., 2006, 16, 2576-2578.

7 S. Konar, N. Bhuvanesh and A. Clearfield, J. Am. Chem. Soc., 2006, 128, 9604-9605(a) S. Konar and A. Clearfield, Inorg. Chem., 2008, 47, 3492-3494; (b) S. Konar and A. Clearfield, Inorg. Chem., 2008, 47, 3489-3491; (c) S. Konar and A. Clearfield, Inorg. Chem., 2008, 47, 5573-5579.

8 (a) Y.-S. Ma, Y. Song, Y.-Z. Li and L.-M. Zheng, Inorg. Chem., 2007, 46, 5459-5461; (b) R. Murugavel, N. Gogoi, K. G. Suresh, S. Lavek and H. C. Verma, Chem.-Asian J., 2009, 4, 923-935.

9 (a) A. Clearfield, Prog. Inorg. Chem., 1997, 47, 371-510; (b) D.M. Poojary, B. Zhang and A. Clearfield, J. Am. Chem. Soc., 1997, 119, 12550-12559; (c) C. V. Krishnamohan Sharma and A. Clearfield, J. Am. Chem. Soc., 2000, 122, 4394-4402; (d) D. Kong, J. Zoñ, J. McBee and A. Clearfield, Inorg. Chem., 2006, 45, 977-986.

10 V. Baskar, M. Shanmugam, M. Helliwell, S. J. Teat and R. E. P. Winpenny, J. Am. Chem. Soc., 2007, 129, 3042-3043.

11 S. Ali, V. Baskar, C. A. Muryn and R. E. P. Winpenny, Chem. Commun., 2008, 6375-6377.

12 (a) Y. Yang, H.-G. Schmidt, M. Noltemeyer, J. Pinkas and H. W. Roesky, J. Chem. Soc., Dalton Trans., 1996, 3609-3610; (b) M. G. Walawalkar, R. Murugavel, H. W. Roeskyand and H.-G. Schmidt, Organometallics, 1997, 16, 516-518; (c) M. G. Walawalkar, R. Murugavel, H. W. Roesky, I. Usón and R. Kraetzner, Inorg. Chem., 1998, 37, 473-478; (d) Y. Yang, J. Pinkas, M. Schafer and H. W. Roesky, Angew. Chem., Int. Ed., 1998, 37, 2650-2653; (e) Y. Yang, J. Pinkas, M. Noltemeyer, H.-G. Schmidt and H. W. Roesky, Angew. Chem., Int. Ed., 1999, 38, 664-666.

13 (a) V. Chandrasekhar and K. Gopal, Appl. Organomet. Chem., 2005, 19, 429-436; (b) M. R. Mason, J. Cluster Sci., 1998, 9, 1-23; (c) R. Murugavel and S. Shanmugan, Chem. Commun., 2007, 1257-1259.

14 (a) L. Merz and W. Haase, J. Chem. Soc., Dalton Trans., 1978, 1594; (b) A. Bencini, D. Gatteschi, C. Zanchini, J. G. Haasnoot, R. Prins and J. Reedijk, J. Am. Chem. Soc., 1987, 109, 2926; (c) R. Wegner, M. Gottschaldt, H. Görls, E.-G. Jäger and D. Klemm, Chem.-Eur. J., 2001, 7, 2143.

15 O. Kahn, Molecular Magnetism, VCH Publisher, New York, 1993p 26. 